\title{
A REFORMA DO ENSINO MÉDIO: UMA LEITURA CRÍTICA DA LEI N. 13.415/2017 - ADAPTAÇÃO OU RESISTÊNCIA?
}

\author{
M. CIAVATTA \\ Universidade Federal Fluminense \\ mciavatta@terra.com.br
}

Submetido 29/03/2018 - Aceito 20/07/2018

DOI: $10.15628 /$ holos.2018.7152

\section{RESUMO}

A reforma do Ensino Médio aprovada pelo governo federal em 2017 requer uma leitura crítica quanto à forma centralizada em que foi concebida e aprovada pelo governo federal. Neste artigo, temos como principal questão a imposição prática de adaptar-se às suas determinações ou resistir à sua aplicação. As duas possibilidades dependem do tratamento que damos à realidade onde construímos nossas vidas, que são históricas e dialéticas. Adaptar-se ou resistir supõe compreender o movimento da vida social na totalidade das relações que constituem a própria reforma, as imposições dos termos da Lei e suas consequências para a formação e o trabalho docente na formação profissional. Supõe apreender o movimento da história, onde ocorre esta e outras reformas, como a trabalhista, o limite dos gastos públicos, o projeto de lei da escola "sem" partido, o desflorestamento, a violência no campo, na vida urbana.
\end{abstract}

São aspectos que fazem parte do contexto econômico e político da Lei e das ações para resistir e subvertê-la. Elas não afetam apenas o ensino médio, mas também a vida e a formação dos professores, o exercício do magistério e as condições de autonomia didático-pedagógica das escolas. Nesta concepção de realidade, não temos respostas prontas, mas temos critérios para refletir sobre as opções e os caminhos que se fecham ou que se abrem aos nossos jovens estudantes, e para a formação e o trabalho docente. Em nossa reflexão, devemos abordar os seguintes aspectos: a história do trabalho e da educação no Brasil e a herança do pensamento escravista; as transformações contemporâneas do mundo do trabalho, o capitalismo dependente e a reforma da legislação trabalhista; o trabalho e a formação docente e a Lei da Reforma do Ensino Médio.

PALAVRAS-CHAVE: Lei da reforma do Ensino Médio; Trabalho e formação docente; Educação Profissional.

\section{THE REFORM OF THE HIGH SCHOOL: A CRITICAL READING OF LAW N. 13.415/2017 - ADAPTATION OR RESISTANCE?}

\section{ABSTRACT}

O The reform of the High School approved by the federal government in 2017 requires a critical reading on the centralized way in which it was conceived and approved by the federal government. In this article, we have as main question the practical imposition of adapting to its determinations or resisting its application. The two possibilities depend on the treatment we give to the reality in which we construct our lives, which are historical and dialectical. To adapt or to resist means to understand the movement of social life in the totality of the relations that constitute the reform itself, the impositions of the terms of the Law and its consequences for the training and the teaching work in the professional formation. It presupposes seizing the movement of history, where this and other reforms take place, such as labor, the limit of public spending, the
\end{abstract}

"no-party" school, deforestation, violence in the countryside, urban life. These are part of the economic and political context of the Law and the actions to resist and subvert it. They affect not only high school, but also the life and training of teachers, the exercise of teaching and the conditions of didactic-pedagogical autonomy of schools. In this conception of reality, we do not have ready answers, but we have criteria to reflect on the options and the ways that close or open to our young students, and for training and teaching work. In our reflection, we must address the following aspects: the history of work and education in Brazil and the heritage of slave thinking; the contemporary transformations of the world of work, dependent capitalism and the reform of labor legislation; the work and the teacher training and the Law of the Reform of the High School.

KEYWORDS: High School Reform Law. Teacher work and training. Professional Education. 


\section{INTRODUÇÃO}

Estes não são tempos normais. Já sabemos que vivemos em um Estado de Exceção (Agamben, 2004), o que significa que a lei máxima que assegura os direitos da população, a Constituição, não é respeitada. Há anomia na convivência civil, há uma desconsideração generalizada com as leis e as normas; há ruptura com os coletivos, defesa do individualismo, centralização autocrática das decisões. Sabemos que a tirania assediada por aqueles que a constituem desmonta a perspectiva democrática em nosso país, mais uma vez, cinco séculos depois de La Boétie.

É o tempo do Escola "Sem" Partido" que pretende amordaçar a atividade e os conhecimentos dos professores, coibir o direito de falar, de divergir, de discutir ideias importantes para a vida social, o papel da escola na formação de crianças e jovens, a relevância das instituições públicas.

Em eventos importantes como este, temos a oportunidade examinar o sentido da resistência possível e das adaptações necessárias para resistir melhor. Saindo da Ditadura CivilMilitar (1964-1985), em um seminário promovido pelo IBASE ${ }^{2}$ entre abril e dezembro de 1991, buscávamos refletir e nos organizar em defesa da democracia. Oliveira (1991) ensinava a defender a democracia como método nas relações Estado e sociedade; como forma de consolidação da esfera pública de convivência; como conteúdo na explicitação de uma perspectiva socialista no trato dos problemas comuns (p. 77, grifos nossos). E mais adiante: "A constituição de uma esfera pública não se dá por decreto. Ela depende, em consonância com os movimentos de complexificação e diversificação societários, da presença e da constituição de fortes sujeitos coletivos" (Oliveira, 1991, p. 86).

A tarefa de que fomos incumbidos neste evento, a leitura crítica da formação e do trabalho docente nos termos da Lei n.13.415/2017, somente pode ser compreendida no contexto de uma esfera pública que se privatiza à revelia de toda normalidade democrática, duramente conquistada nos últimos 35 anos.

A pergunta fundamental diante da lei e de seu contexto é: devemos nos adaptar ou resistir? As duas respostas possíveis supõem o trato com a realidade e o real onde construímos nossas vidas, e nossas formas de ser, são históricas e dialéticas. Significa que estamos lidando sempre com o mundo e seus acontecimentos em um movimento permanente de transformação, nossa e de tudo que nos rodeia física ou virtualmente.

Portanto adaptar-se ou resistir supõe compreender esse movimento na totalidade das relações que constituem a própria reforma, as imposições nos termos da lei e suas consequências para a formação e o trabalho docente na formação profissional. O movimento da história, onde ocorre esta reforma, o projeto de lei da escola "sem" partido, a reforma das leis do trabalho e outras contrarreformas no campo, nas florestas brasileiras, na malha urbana industrial, fazem parte da submissão a seus termos e das ações para resistir ou subvertê-la.

\footnotetext{
${ }^{1}$ Projeto de Lei n. 867/2015. V. Frigottto (2017), Escola “Sem" Partido.

2 Instituto Brasileiro de Análises Socioeconômicas (IBASE), na época, coordenado por Betinho.
} 
Não podemos falar em contrarreforma do ensino médio sem refletir sobre os processos políticos em curso no país. Eles não afetam apenas o ensino médio, mas também a vida e a formação dos professores, o exercício do magistério e as condições de autonomia didáticopedagógica das escolas.

Nesta concepção de realidade, não temos respostas prontas, mas temos critérios para refletir sobre as opções, sobre os caminhos que se fecham ou que se abrem aos nossos jovens estudantes, e para a formação e o trabalho docente. Em nossa reflexão, devemos abordar os seguintes aspectos: a história do trabalho e da educação no Brasil; as transformações contemporâneas do mundo do trabalho e a reforma da legislação trabalhista; o trabalho e a formação docente e a reforma do ensino médio. Adaptar-se ou resistir é a questão que nos desafia.

\section{A HISTÓRIA DA EDUCAÇÃO E DO TRABALHO NO BRASIL}

Através de uma visão histórica, podemos nos aproximar das razões porque o Brasil, com todas as riquezas naturais e abundante força de trabalho, apresenta desigualdades sociais entre as mais elevadas do conjunto das nações. Hoje, diante das últimas medidas recessivas, do desemprego e da legislação aprovada contra os direitos conquistados ao longo do século XX, os dados de 2011 estão sendo duramente agravados.

Eles podem ser lidos à luz dos processos sociais controvertidos, após a crise econômica mundial e os governos petistas Lula da Silva e Dilma Rousseff (2003-2015). Alguns dados publicados na imprensa, na época indicam que somos o país com o mais alto grau de desigualdade no mundo, embora, pelos dados oficiais, nos últimos períodos governamentais, tenham sido retirados 9 milhões de brasileiros da miséria e 20 milhões da pobreza; mas 45,7\% dos domicílios ainda não têm acesso ao saneamento básico e $70 \%$ dos problemas de internação junto ao Sistema Único de Saúde (SUS) decorrem da ausência de acesso à água potável; o analfabetismo vai a $4,4 \%$ na população urbana, chegando a $22,8 \%$ na rural; e pela concentração de renda, que completa estes breves exemplos de desigualdade social, os $10 \%$ mais ricos ficam com $42,8 \%$ da renda, enquanto os $10 \%$ mais pobres ficam com 1,3\% (Piovesan, 2011).

Diante desse quadro e do retrocesso político e social em curso o país, após do Golpe de 2016, não podemos ser inocentes sobre a história trágica de nosso país. Submetido à Colônia, ao Império, à escravidão e à República instaurada no final do século XIX, manteve-se o trabalho livre no antigo padrão escravocrata, sem regulação dos direitos dos trabalhadores. ${ }^{3}$

Há uma depreciação histórica do trabalho manual, bem evidenciada no trabalho de Cunha (2000). Os trabalhadores manuais, profissionais e técnicos e nós, como parte da sociedade brasileira, diante das elites mandatárias do país, herdamos dos tempos coloniais, imperiais e republicanos, uma sociedade onde prevalece a desvalorização econômica e social (baixos salários, status social inferior, educação elementar educação profissional fragmentada) em amplos setores da população.

\footnotetext{
${ }^{3}$ Esta seção tem por base Cunha (2000), e Ciavatta e Reis (2017).
} 
O antropólogo Milton Guran, considera que todas as respostas estão no Cais do Valongo: "O maior porto escravagista da história da humanidade". Por ali, teriam entrado no país um milhão de pessoas trazidas da África entre 1811 e 1843. ${ }^{4}$ Os que chegavam mortos, eram enterrados ali mesmo, "um aterro sanitário, no chamado Cemitério dos Pretos Novos" (Azevedo, 2017, p. 17).

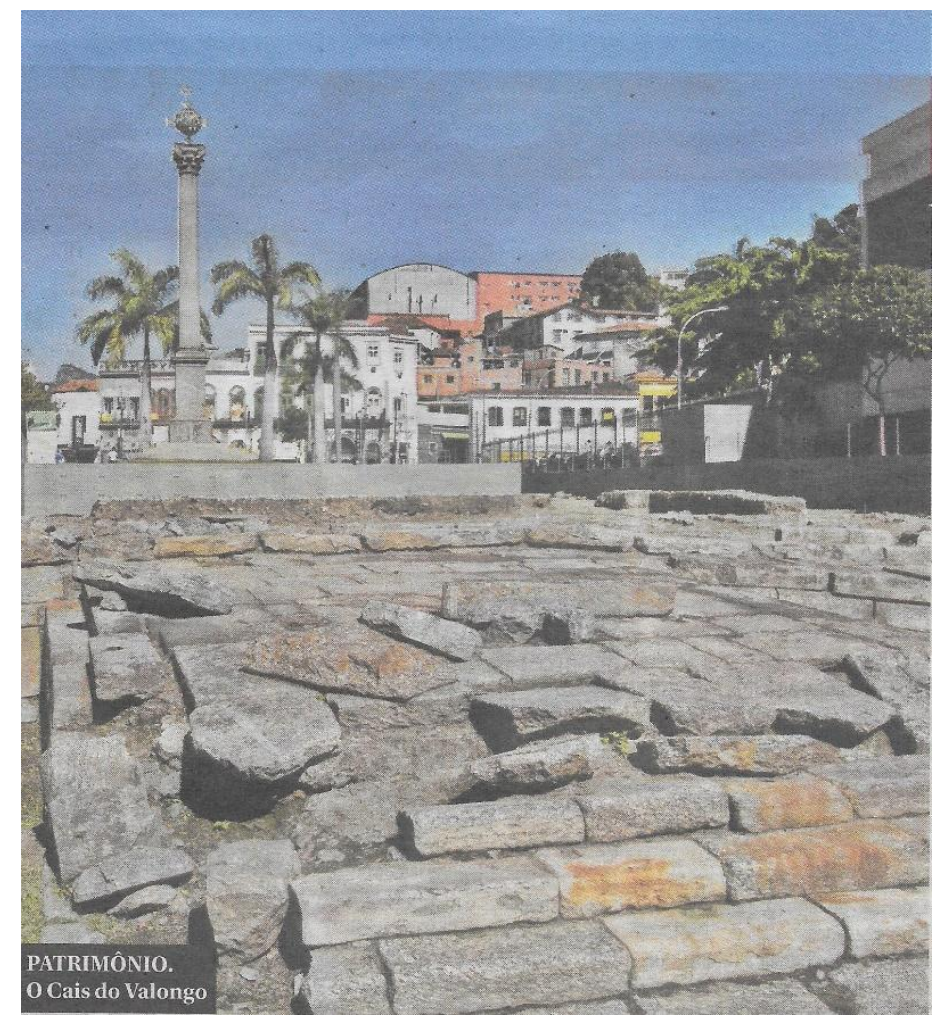

Figura 1: Pequena África Carioca, de Fernando Lemos. Fonte: O Globo, Rioshow, 21 jul., p. 15.

As marcas da opressão escravista se fazem presentes até hoje na privação de serviços básicos de moradia, saúde, educação, segurança, participação política e social no incipiente processo de institucionalização democrática. Do ponto de vista do trabalho que gera toda riqueza social, as políticas escravistas contribuíram para o afastamento da força de trabalho livre do artesanato e da manufatura. Os homens brancos e livres se negavam a assumir este tipo de trabalho para, assim, se diferenciarem da condição de escravo.

As marcas da opressão escravista contribuíram para afastar a força de trabalho livre do artesanato e da manufatura. Os homens brancos e livres se negavam a assumir este tipo de trabalho para, assim, se diferenciarem da condição de escravo. Produziu-se no país uma estrutura de classes diferenciada econômica e socialmente, marcada pela discriminação ideológica étnica e cultural. São alicerces que instauraram padrões de comportamento na vida pública e privada e nas relações familiares.

\footnotetext{
4 “Proporcionalmente, comparando com os índices demográficos daquela época e hoje, um número atualizado de 12 milhões" (Azevedo, 2017, p. 17).
} 
A história do autoritarismo e da permanência da separação aguda da população dos benefícios sociais da riqueza evidencia que, através dos séculos, de geração em geração, buscouse consolidar o poder patriarcal das oligarquias latifundiárias e empresariais no mundo político e no padrão de vida da população.

Mas a visão do escravo como um ser coisificado, subjugado por seu senhor, incapaz de protagonizar sua própria história, pensar e agir por si e para si, dá lugar também a sujeitos que redefinem significados culturais e políticos que se manifestam através de diferentes percepções sobre liberdade e sobre a conjuntura política e social em que estavam inseridos (Ciavatta \& Reis, 2017).

O resgate da memória da escravidão, a reapropriação da própria história e da presença do negro na sociedade brasileira, somam-se às revoltas do início do século XX (entre outros, REIS, 2003) e à resistência dos grupos quilombolas. Chalhoub e Silva (2009) chamam a atenção para a forma como os trabalhadores escravizados souberam utilizar em proveito próprio as contradições presentes no Estado Imperial, lutando por seus direitos através dos mesmos mecanismos ou instituições que garantiam a continuidade da hegemonia da classe senhorial.

Gorender (2016) polemiza com Chalhoub e outros historiadores sobre a colaboração dos escravos com os senhores, nas ações de paternalismo ou patriarcalismo, nos termos de Gilberto Freyre ("Casa Grande \& Senzala", 1933). Também Maestri (2016) contesta "As teses de Gilberto Freire, tecidas a partir de 1933, de um escravismo patriarcal, benigno e consensual" (Gorender, 2016, p. 10). Acrescenta que

as lutas dos escravos não podiam transcender as limitações estruturais da posição de explorados. Enquanto teve base econômica sólida, coesão interna e apoio internacional, a formação social escravista enfrentou essas lutas e as sufocou. Mas, nem por isto, a resistência dos escravos deixou de agir no sentido de desgastar o regime opressor e impor limitações à sua expansão (Gorender, 2016, p. 152). ${ }^{5}$

Temos que convir que a regressão nos direitos trabalhistas, educacionais, previdenciários a que estamos sujeitos a partir do Golpe de 1916, tem antigas raízes no tecido social brasileiro. Elas alimentam as relações de classe, a forte desigualdade social e a permanência dos privilégios das elites até os dias de hoje.

Não obstante as lutas e conquistas, os estudos sobre o mundo do trabalho, a educação e a história das políticas educacionais ${ }^{6}$ em curso, particularmente, do ensino médio e da educação

\footnotetext{
${ }^{5}$ Recentemente, Mamigonian (2017), relata que a Lei de 1831, a Lei Euzébio de Queiroz, que proibiu o tráfico de escravos, não foi nunca cumprida. O Estado imperial brasileiro ignorava a entrada constante de novos escravos e recebia pagamentos dos senhores das cidades e das fazendas, que utilizavam os "pretos livres" de direito pela lei de 1831, nos serviços domésticos, como trabalhadores alugados ou em suas fazendas. A autora dá o nome de escravos e de senhores da corte em conluio com o Império, que participavam do processo que prolongou a formação social escravista no Brasil.
}

${ }^{6}$ Esta reflexão tem por base Ciavatta $(1998,2016)$. 
profissional evidenciam a permanência das diferentes classes sociais. Elas se enraízam na materialidade dos baixos salários, das precárias condições de vida, no preconceito contra o trabalho manual desqualificando os trabalhadores da base da pirâmide social em que nos constituímos como povo brasileiro.

O objetivo de diluir os conflitos sociais e manter a "ordem e progresso" a qualquer custo está inscrito nas políticas de educação e do trabalho que, historicamente, destina-se às classes de baixa renda: a educação profissional como uma formação funcional às necessidades do mercado, formação aligeirada na forma de cursos breves, em detrimento da universalização do ensino médio de qualidade para todos.

A compreensão de um fato não implica a solução do problema que ele contém, mas concorre para organizar forças para sua solução. Esta seria uma das razões que explicam porque as elites no poder só cuidam da educação em função de seus interesses. É o que temos hoje na educação corporativa expandida para todos os níveis educacionais, na formação das competências para o mercado, nas restrições a uma educação pública de qualidade. Avolumamse os programas de formação restritos aos aspectos instrumentais e, mesmo esses, com uma base mínima de conhecimentos, comparáveis ao analfabetismo funcional, pela restrita educação profissional, em um contexto de desenvolvimento científico e tecnológico no mundo produtivo. ${ }^{7}$

No Prefácio ao livro Todos pela Educação (Martins, 2016), Luiz Carlos de Freitas (2016) reafirma a presença antiga dos grupos empresariais na definição dos rumos da educação brasileira. Mas, hoje, aumentou o protagonismo "dos meios empresariais no âmbito político e social, em especial através da criação de fundações, organizações sociais e de financiamento de iniciativas que encampem as teses empresariais no campo da Educação" (Freitas, 2016, p. 9).

Toda iniciativa que possa alargar a compreensão dos acontecimentos que moldam a sociedade, é postergada, eliminada. São exemplos recentes as reformas da educação ao arrepio da Lei de Diretrizes e Bases (LDB), os cortes no financiamento aos institutos e às universidades federais, a repressão aos estudantes e professores contrários à deterioração das escolas, ao descaso, às reformas privatizantes.

\section{AS TRANSFORMAÇÕES CONTEMPORÂNEAS DO MUNDO DO TRABALHO E A REFORMA DA LEGISLAÇÃO TRABALHISTA}

São muitas e impactantes as transformações contemporâneas do mundo do trabalho e da vida social que atingem a todos, ricos e pobres, mas os atinge de forma diferenciada, segundo a apropriação dos bens produzidos pela sociedade como um todo. Assim, os problemas

\footnotetext{
7 São considerados analfabetos funcionais aqueles que "não conseguem realizar tarefas simples envolvendo leitura de palavras e frases. Alguns conseguem ler números". Catarina Pignato, Vitória Ostetti e Daniel Mariani. A evolução do analfabetismo funcional no Brasil. Nexo Jornal. Recuperado de: <https://www.nexojornal.com.br/grafico/2016/11/21/A-evolu\%C3\%A7\%C3\%A3o-do-analfabetismo-funcional-noBrasil>..
} 
econômicos estão imbricados com as transformações do mundo do trabalho e com suas repercussões político-ideológicas.

Traremos alguns aspectos da questão econômica relativos ao Golpe político, midiático e jurídico que depôs uma governante legitimamente eleita, Dilma Rousseff. Instalou-se o governo ilegítimo, de Michel Temer e seu grupo político comprometido em graves processos judiciais. Deflagrou-se um conjunto de políticas afins com a situação de capitalismo dependente do país, a começar pela privatização de empresas e serviços, e as reformas da legislação trabalhista, da educação, da previdência social.

Analisando o momento atual, Bava (2015) discute o que chama de "falsa polarização" entre esquerda e direita, as manifestações neoliberais verde-amarelo e de ódio aos petistas e aos sindicatos. $\mathrm{O}$ autor explica em detalhes a gênese econômica que tomou corpo no Golpe em curso nas instituições brasileiras. O que não estaria claro e visível na polarização das classes sociais e seus objetivos são os interesses dos bancos e das grandes empresas.

As empresas com ações na Bolsa de Valores de São Paulo tiveram o aumento de $46 \%$ em seus lucros em 2014. No mesmo ano, a exemplo, os bancos, tiveram grandes lucros, cerca de $26 \%$, o Itaú, e $30 \%$, o Safra, considerando que a economia, como um todo, teve o crescimento do Produto Interno Bruto (PIB) próximo a zero.

A explicação é simples se não fosse dramática para o cidadão comum: "Essa rentabilidade depende muito da taxa $S \operatorname{lic}^{8}$, que remunera a dívida pública, e das taxas cobradas pela intermediação financeira sobre empréstimos e financiamentos pelos bancos" (op. cit., p. 3). 0 governo federal, diante da crise econômica internacional, em 2009, reduziu a taxa Selic; mas sofreu pressões para aumentá-la; em 2011, retomou a política de baixar os juros. "Como consequência, 2014 apresentou o menor superávit primário desde 1999, ou seja, a menor remuneração para os rentistas" (ibid.).

Outras medidas que desagradaram os grandes proprietários do capital (associados ao capitalismo internacional), foram as ações dos bancos públicos, Caixa e BNDES, particularmente,

que aumentaram o crédito, baixaram os juros e ganharam mercado. Os bancos públicos, de $35 \%$ do mercado que detinham em 2009, chegaram a 55\% em 2015. O congelamento do preço da gasolina e da eletricidade tem o mesmo sentido, de preservar a capacidade de compra das pessoas e manter o dinamismo do mercado interno, e também contrariou interesses das empresas concessionárias (ibid.)

\footnotetext{
${ }^{8}$ A Selic é a taxa básica de juros da economia no Brasil, utilizada no mercado interbancário para financiamento de operações com duração diária, lastreadas em títulos públicos federais. A sigla SELIC é a abreviação de Sistema Especial de Liquidação e Custódia, um sistema computadorizado utilizado pelo governo, a cargo do Banco Central do Brasil, para que haja controle na emissão, compra e venda de títulos. Recuperado de: < https://www.tororadar.com.br/investimentos/taxa-selic-o-que-e-rendimento>.
} 
Para finalizar Bava (ibid.) acrescenta que "o grande empresariado e o setor financeiro se uniram contra a redução da rentabilidade do rentismo, contra as políticas anticíclicas ${ }^{9}$, contra o governo Dilma". Assim, o autor explica a inconformidade com o resultado das eleições de 2014 e as políticas dos opositores que desestabilizaram o governo.

A crise da institucionalidade democrática do país, contou também com outros fatores: com o conservadorismo da classe média, com a campanha midiática moralizante, com os interesses partidários dos políticos envolvidos na corrupção, e até com a partidarização do judiciário. Essas considerações de ordem econômica, não explicam toda polarização social, mas ajudam a entender o que teóricos como Florestan Fernandes e Rui Mauro Marini analisam como "capitalismo dependente".

O impacto das ciências, das novas tecnologias e do desenvolvimento científico ${ }^{10}$ na produção e na vida do trabalhador brasileiro devem ser vistos no contexto do capitalismo econômico financeiro existente na ordem internacional de que o país participa. Apesar de bastante divulgada nos dias de hoje, é indispensável conhecer o que os estudiosos chamaram de capitalismo dependente para entender os desvarios econômicos a favor do rentismo que domina o Brasil nesta segunda década do século XXI.

A explicitação da dependência econômica e política dos países não desenvolvidos ou em desenvolvimento, em relação aos países de desenvolvimento avançado que, com variações interpretativas tomou o nome de "teoria da dependência" foi a primeira elaboração dessa concepção. ${ }^{11}$ Entre outros méritos, está o reconhecimento de ser uma reflexão gerada na América Latina, a partir dos problemas latino-americanos, em sua relação com os países do capitalismo central.

"Capitalismo dependente" é seu melhor título, conforme o tratamento que the dão Florestan Fernandes e Rui Mauro Marini. É a dependência econômica e cultural que torna o país refém das imposições dos organismos internacionais. Fernandes (1972), elucida como o capitalismo dependente constitui-se, enquanto sociedade de classes, em uma formação histórico-social que se caracteriza pela sobreapropriação do excedente econômico e pela superexploração do trabalho.

Para o autor as sociedades latino-americanas estruturam-se internamente de forma que, embora absorvam as transformações do capitalismo, nem por isso logram desenvolver a integração nacional e alcançar a realização de um projeto nacional autônomo. De outra parte, a dominação externa também estimula um processo de modernização das forças produtivas que alimenta a ilusão desenvolvimentista mas que, em realidade, reforça a dependência e consolida o imperialismo ao invés de superá-lo.

\footnotetext{
9 "Política anticíclica é aquela que se dispõe a criar condições para que a economia produza efeitos compensatórios diante de desequilíbrios macroeconômicos. Se estiver crescendo demais, acionam-se mecanismos para reduzir a atividade, como retração do crédito, aumento de impostos e dos juros". Disponível em: <www.updatepolitics.cc/>. Acesso em: 23 jul. 2017.

10 Para maiores detalhes sobre o assunto, v. Pirro e Longo, 2007.

${ }^{11}$ Esta seção tem por base Ciavatta e Trein, 2011.
} 
O autor considera a situação histórica de "imperialismo total" e destaca seus traços mais marcantes:

(...) ele organiza a dominação externa a partir de dentro e em todos os níveis da ordem social, desde o controle da natalidade, a comunicação de massa e o consumo de massa, até a educação, a transplantação maciça de tecnologia ou de instituições sociais, a modernização da infra e da superestrutura, os expedientes financeiros ou do capital, o eixo vital da política nacional etc. Segundo, esse tipo de imperialismo demonstra que mesmo os mais avançados países latino-americanos ressentem-se da falta dos requisitos básicos para o rápido crescimento econômico, cultural e social em bases autônomas (Fernandes, 1972, p. 18).

O pensamento de Marini (2000) nos ajuda a pensar sobre outros detalhes das causas da subordinação, da natureza da dependência e de suas implicações para os trabalhadores. 0 incremento da indústria no século XIX, nos países centrais, se fez às custas do fornecimento de produtos de subsistência de origem agropecuária e da massa de matérias primas proporcionadas, em grande parte, pelos países latino-americanos. De modo contrário, nos países centrais, o Estado investiu na educação básica da população e na sua formação para a elevação da produtividade dos trabalhadores.

Em países como o Brasil, para fazer frente aos processos internos de reprodução do capital internacional e de seus aliados nas sociedades dependentes, a organização da classe trabalhadora, esbarra na superexploração do trabalho. Para Marini (2000) três fatores expressam esta particularidade das sociedades dependentes:

(i) o aumento da intensidade do trabalho aparece como um aumento da mais-valia, através de maior exploração do trabalhador e não pelo aumento de sua capacidade produtiva, pela sua educação;

(ii) uma maior exploração da mais-valia absoluta em sua forma clássica se manifesta pela prolongação da jornada de trabalho e o aumento do trabalho excedente;

(iii) um terceiro procedimento consiste em reduzir o consumo do trabalhador além de seu limite normal, o que o obriga a um tempo maior de trabalho excedente que se transforma "em um fundo de acumulação do capital" (Marx, O Capital, I, XIV, grifos no original, apud Marini, pp. 123-124).

Estes fatores configuram sociedades baseadas na superexploração do trabalho e não no desenvolvimento das forças produtivas, tal como se dá nos países de alto desenvolvimento científico-tecnológico. A transferência para os países periféricos de setores industriais com baixo valor agregado em ciência e tecnologia permitiu o desenvolvimento das forças produtivas sem que isso impactasse a força de trabalho no sentido de reduzir a sua superexploração, mas de incluí-la na sociedade de consumo. É o que observamos hoje depois de duas décadas de governos neoliberais. 
Estas questões de ordem mais geral são necessárias para entendermos a gravidade das medidas tomadas pelo Governo do Golpe de 2016, a ponto de um sindicalista expressar seu sentimento de devastação dizendo que "Nem na ditadura militar houve uma ofensiva tão grande contra os direitos dos trabalhadores e suas representações sindicais". A reforma trabalhista ${ }^{12}$ ocorreu no melhor modelo corporativo-jurídico, sem qualquer tipo de discussão com a sociedade, à revelia das manifestações coletivas, e foram muitas. Apenas agradou à elite empresarial e financeira (Patah, 2017).

Seremos o "país jabuticaba ?" pergunta ele. ${ }^{13}$ A metáfora se aplica porque somente o Brasil teve "o maior porto escravagista da história da humanidade"14, o Cais do Valongo, no Rio de Janeiro. A ideia é uma analogia à destruição histórica dos direitos dos trabalhadores. De um lado, a reforma trabalhista é conforme às reformas capitalistas em nível mundial, a exemplo da França, da Itália, no sentido do aumento desmedido da produtividade e da rentabilidade do capital; de outro, pela volta às condições de semiescravidão do início do século $\mathrm{XX}$, embora estejamos na segunda década do século XXI.

A adaptação à Lei é o garrote das gerações de jovens que se preparam para entrar no mercado do trabalho. Resistir à Lei é, antes de tudo conhecer a história que a antecede e que foi fruto de lutas e conquistas dos trabalhadores e de seus coletivos sindicais. Tão importante quanto conhecer as ciências e as tecnologias da formação profissional, é conhecer os meandros mentirosos da Lei a favor dos empregadores, buscar meios coletivos de se opor a eles e garantir direitos.

Destes, destacaremos alguns aspectos (Patah, 2017): a reforma vai aumentar empregos, diz o governo. Com a economia em recessão, e 14 milhões de desempregados, não há perspectiva de criação de empregos e de boa remuneração. Quando muito, aumentarão os empregos precarizados, por tempo determinado, por dia, por horas, em negociação direta com o empregador que detém o poder para contratar e para demitir.

A Lei agrega mais um dado antissocial do atual governo. Sabemos que apenas investimentos produtivos geram empregos. Mas essa perspectiva está comprometida com a aprovação, em 13 de dezembro de 2016, da Emenda Constitucional n. 95, chamada de Teto dos Gastos Públicos. ${ }^{15}$ Significa uma contenção nos investimentos em saúde e educação, nos gastos sociais, nos reajustes do salário mínimo. Se o limite de gastos não for mantido, órgãos, estados e municípios ficam impedidos no exercício seguinte de reajustar salários, contratar pessoal, fazer concursos públicos e criar novas despesas. A retirada de direitos, a perda de serviços essenciais

\footnotetext{
${ }^{12}$ A Lei no 13.467 de 14 de julho de 2017 altera a Consolidação das Leis do Trabalho (CLT), aprovada pelo Decreto-Lei no 5.452, de 10 de maio de 1943., também chamada de Lei de Modernização Trabalhista, está publicada na edição de sexta-feira, 14 de julho de 2017, Diário Oficial da União.

13 O termo "capitalismo jabuticaba" reproduz a metáfora de Cláudio Moura Castro, "ensino médio jabuticaba" só tem aqui, no Brasil.

14 Expressão do antropólogo Milton Guran (apud Azevedo, 2017)“Cais do Valongo, o útero do país”. O Globo, Rio, 12/07/2017, p. 17.

${ }^{15}$ A PEC n. 241 (Proposta de Emenda Constitucional) na Câmara dos Deputados e PEC n. 55 no Senado Federal, a EC n. 95 congela por 20 anos as despesas do Governo Federal, corrigidas pela inflação acumulada medida pelo IPCA (Índice de Preços ao Consumidor Amplo), sob a justificativa da contenção das contas públicas.
} 
vai agravar a situação da população em progressivo empobrecimento. ${ }^{16}$ Mas não se altera o superávit primário para o pagamento da dívida pública, garantindo os lucros do capital rentista, nem inibiu o presidente ilegítimo de antecipar generosos aumentos para o poder judiciário e legislativo como foi noticiado pela imprensa.

A Lei no 13.467 /2017, a Lei da Reforma Trabalhista, retira dos sindicatos o poder de negociação coletiva. A homologação das demissões não precisará mais passar pelos sindicatos. A negociação individual vai prevalecer sobre a Consolidação das Leis do Trabalho (CLT), no trato com as questões de contrato para trabalho intermitente por dias ou horas, jornada de trabalho, intervalo para almoço, planos de cargos e salários; condições de insalubridade para gestantes.

Logo após a aprovação da Lei começaram as demissões no Bradesco, na Caixa Econômica Federal e no Banco do Brasil através de planos de demissão voluntária. A propalada criação de empregos na agricultura faz referência à legislação antiga que foi apagada (Patah, op. cit.).

Não existem recursos para os serviços essenciais: saúde, educação, segurança. No entanto, o governo pagou regiamente, o valor de 15,3 bilhões para estados e municípios da base aliada e 1,9 bilhão para programas e emendas dos parlamentares antes da votação na Comissão de Constituição e Justiça, (Barreto et al., 2017). Embora a oposição resista, os apoiadores atuam como se fosse normal "a compra de votos" no Legislativo "para não perder ou conseguir cargos para correligionários" (Patah, ibid.).

A quase anomia nas relações de trabalho, de acordo com a nova Lei, agrava o que já fora definido pela Lei no 13.429/2017 de 31 de março de 1917, a lei da Terceirização 17: "a possibilidade de as empresas terceirizarem a chamada atividade-fim, aquela para a qual a empresa foi criada. A medida prevê que a contratação terceirizada possa ocorrer sem restrições, inclusive na administração pública". (Esposito, 2017). Esta norma de Lei amplia a terceirizações que já vêm ocorrendo, desobriga a empresa contratante das obrigações trabalhistas, conduz à instabilidade no emprego, ao individualismo e dilui os planos e projetos coletivos.

\section{O TRABALHO, A FORMAÇÃO DOCENTE E A REFORMA DO ENSINO MÉDIO}

Como a Lei da Terceirização que teve seu primeiro texto elaborado em 1998, no governo neoliberal de F. H. Cardoso (1995-2002), a Lei da Reforma do Ensino Médio, Lei n. 13.415 de 18 de fevereiro de 2017, teve sua gênese no contexto das reformas neoliberais, nos programas de

\footnotetext{
16 “O comércio fechou 9.950 lojas neste primeiro momento. Os bancos desativaram 928 agências bancárias. Até o setor automotivo, que está exportando, demitiu mais de 6.000 trabalhadores ao longo dos últimos 12 meses, Há no país cerca de 14 milhões de desempregados" (Patah, 2017). O autor é Presidente da União Geral dos Trabalhadores (UGT), criada em 2007, uma dissidência de centro-esquerda, "a segunda maior central sindical do país, é a favor das reformas" (ibid.)

17 O Substitutivo do Senado ao Projeto de Lei no 4.302-B, de 1998, que altera dispositivos da Lei no 6.019, de 03 de janeiro de 1974, que dispõe sobre o trabalho temporário nas empresas urbanas e dá outras providências, e dispõe sobre as relações de trabalho na empresa de prestação de serviços a terceiros. Foi transformado na Lei Ordinária n. 13.429/2017 de 31 de março de 1917, a lei da Terceirização. A Procuradoria Geral da República (PGR) ingressou no Supremo Tribunal Federal (STF) com ação direta de inconstitucionalidade contra a aprovação da Lei. Não sabemos o resultado.
} 
reestruturação produtiva, ajuste fiscal, no corte de custos e deterioração da educação básica pública, na ampliação do espaço à privatização a partir dos anos 1990.

O trabalho e a formação dos professores, incluindo os de educação profissional, ocorrem na historicidade do tempo-espaço das sociedades a que pertencem. Sociedade são coletivos que se formam para a produção dos bens materiais, intelectuais, afetivos, religiosos etc., para a manutenção da vida e de seus significados, para a solução de seus múltiplos problemas. Não obstante todas as promessas de um país grandioso em riquezas naturais, como o Brasil, as perspectivas históricas supõem ainda uma longa caminhada na conquista da dignidade de vida, trabalho, educação e saúde para toda a população

Como colônia de exploração da nação portuguesa, o Brasil se constituiu como um país dependente, primeiro, da metrópole, depois, sob o regime monárquico, das nações europeias que aqui aportaram para explorar riquezas para os países colonizadores e trazer o "progresso" a que se aspirava nos séculos a partir das doutrinas do lluminismo. A ideia da institucionalidade democrática é tardia no Brasil e seu desenvolvimento incerto, diante dos inúmeros golpes políticos e militares que aconteceram no país, a favor das elites enriquecidas.

Do ponto de vista da educação e da educação profissional que aqui nos interessa particularmente, o Estado avantajou-se na centralização e no controle dos recursos, na avaliação da produção do conhecimento e das práticas educativas dos professores. Somadas às condições de trabalhos desarticuladas pelas reformas trabalhista e educacional, é este o conjunto de relações que constituem a totalidade social onde o trabalho docente se exerce com a perda progressiva de autonomia e ingerência do poder institucional no cotidiano dos professores.

Nos limites deste trabalho, destacaremos alguns aspectos da Lei da Reforma do Ensino Médio, com a advertência de que embora afirmativos, seus termos não são a expressão da verdade absoluta. A ação educativa permanecerá sempre como um espaço de trabalho, de criação mediado pelos conhecimentos específicos e pelos saberes gerados na prática docente de cada professor.

Na nova lei, retoma-se o termo "formação profissional" (Art. 4‥) em vez de educação profissional introduzido com a LDB, Lei n. 9.394/96, voltando ao termo tradicional na preparação para o trabalho. Nos anos 1990, criticamos a substituição do termo formação profissional por educação profissional. É um sinal daqueles tempos onde o conceito amplo de educação como formação humana foi ressignificado na LDB, a Lei n. 9.394, como se a formação profissional fosse uma formação plena, e não apenas preparação para o mercado de trabalho (Ciavatta, 1998), como tomou forma na implementação aguda do Decreto n. 2.208/97. A ideia foi amplamente divulgada, ao arrepio das práticas formativas, pelo PLANFOR, programa de educação profissional fragmentada em módulos e em tempos breves, até a criação de seu programa similar, o Pronatec.

Talvez, o que mais chama a atenção na Lei é o Art. 4‥ que altera o Art. 36 da LDB (Lei n. 9.394/96), e "oferta as seguintes áreas de conhecimento: I - linguagens e suas tecnologias; IImatemática e suas tecnologias; III- ciências da natureza e suas tecnologias; IV - ciências humanas e sociais aplicadas; $V$ - formação técnica e profissional". Este sistema de opções prematura para os jovens, conduz à opção pelas ciências e humanidades aos alunos que podem preparar-se para 
o ensino superior; e à opção técnica e profissional para os que precisam entrar mais cedo para o mundo do trabalho e suas adversidades.

O Art. 4․ . da Lei reitera a reforma da educação dos anos 1940, a Reforma Capanema, que separava os alunos do ensino médio no Clássico e no Científico, preparando para as duas principais áreas do ensino superior, as humanidades e as ciências da natureza. Em paralelo, ofertava-se a formação profissional com a Leis Orgânicas do Ensino Industrial (1942), do Ensino Comercial (1946) e do Ensino Agrícola (1946).

No mesmo artigo, dentro do Inciso V (formação técnica e profissional), o inciso II do parágrafo 6, admite "a possibilidade de concessão de certificados intermediários de qualificação para o trabalho", alimentando a fragmentação ainda maior da formação de nível médio. Esta perde para os mais pobres os objetivos de educação básica. No parágrafo 10, reforça-se esta tendência segmentadora ao admitir que "o ensino médio poderá ser organizado em módulos e adotar o sistema de créditos com terminalidade específica".

A mesma tendência se reforça opcionalmente, no mesmo artigo 4‥, parágrafo 11, inciso VI, admitindo "cursos realizados por meio de educação à distância ou educação presencial mediada por tecnologias".

$\mathrm{O}$ art. 60. Inciso IV, altera o art. 61 da LDB, admitindo no magistério "profissionais com notório saber" ou, no Inciso V, "graduados que tenham feito complementação pedagógica". Estará resolvido, assim, o problema da falta de professores nas disciplinas Matemática, Física, Química, Biologia, onde os graduados podem ter melhores ofertas de trabalho nos setores produtivos?

Já admitindo a aprovação da reforma trabalhista, ocorrida em julho, para a reforma do ensino médio, aprovada em fevereiro, no seu art. 8o, altera o Art. 318 da CLT (Decreto-Lei n. 5.452 , de 1‥ de maio de 1943). Trata do "intervalo para refeição", enquanto análises sobre a nova lei consideram que a "Negociação vai prevalecer sobre a CLT quando tratar de temas como jornada, intervalo para almoço e plano de cargos, salários e funções".

Estes comentários não esgotam a complexidade da lei e das mudanças normativas. Mas, principalmente, não alcançam as consequências negativas e positivas de sua implementação nas escolas que não se esgotam no texto legal. Implícita ou explicitamente, a lei é interpretação na gestão coletiva e na prática dos professores na sala de aula.

\section{CONSIDERAÇÕES FINAIS}

Como ponto de partida desta leitura crítica da reforma do Ensino Médio em curso, reiteramos que não existem respostas prontas, as respostas possíveis dependem da história onde, coletiva e individualmente, produzimos nossos meios de vida. Mas, se não temos respostas acabadas, temos critérios para refletir sobre as opções, sobre os caminhos que se fecham ou que se abrem aos nossos jovens estudantes, e para a formação e o trabalho docente. 
As ações devem surgir da prática refletida, desafiada pelo Golpe parlamentar, jurídico e midiático de 2016, conduzido com tirania, pelo ilegítimo governo Temer e pelos partidos que o apoiam, em troca de benesses, sem ouvir os diversos segmentos sociais que se manifestaram

As marcas da opressão escravista se fazem presentes até hoje no incipiente processo de institucionalização democrática, no autoritarismo dos governos, na privação de serviços básicos (moradia, saúde, educação, segurança), de participação política e social. Do ponto de vista histórico do trabalho que gera toda riqueza social, as políticas escravistas contribuíram para o preconceito contra o trabalho manual, para o afastamento dos homens brancos e dos negros livres que se negavam a assumir este tipo de trabalho para, assim, se diferenciarem da condição de escravo. São marcas inscritas nas políticas de educação profissional que, historicamente, destina-se às classes de baixa renda: uma formação funcional às necessidades do mercado, formação aligeirada na forma de cursos breves, em detrimento da universalização do ensino médio de qualidade para todos.

O impacto das ciências, das novas tecnologias e do desenvolvimento científico na produção e na vida do trabalhador brasileiro devem ser vistos no contexto do capitalismo econômico financeiro existente na ordem internacional de que o país participa de modo subordinado. Apesar de bastante divulgada nos dias de hoje, é indispensável conhecer o que os estudiosos chamaram de capitalismo dependente para entender os desvarios econômicos a favor do rentismo que domina o Brasil nesta segunda década do século XXI.

Nas análises do capitalismo dependente, países como o Brasil, para fazer frente aos processos internos de reprodução do capital internacional e de seus aliados, a organização da classe trabalhadora esbarra em várias dificuldades. Elas estão expressas na superexploração do trabalho, nos baixos salários e más condições de vida, na baixa escolaridade mantida pelo Estado que furta-se a oferecer uma educação de qualidade para toda a população.

No conjunto, além da herança histórica, as reformas em curso inserem-se nas políticas afins com a situação de capitalismo dependente do país, a começar pelo Teto dos Gastos Públicos, a privatização de empresas e serviços, e as reformas da legislação trabalhista, da educação, da previdência social. A crise da institucionalidade democrática do país, contou também com outros fatores: com o conservadorismo da classe média, com a campanha midiática moralizante, com os interesses partidários dos políticos envolvidos na corrupção, e até com a partidarização do judiciário.

Do ponto de vista da educação e da educação profissional que aqui nos interessa particularmente, o Estado avantajou-se na centralização e no controle dos recursos, na avaliação da produção do conhecimento e das práticas educativas dos professores. Somadas às condições de trabalhos desarticuladas pelo limite dos gastos públicos, pelas reformas trabalhista e educacional, este é o conjunto de relações que constituem a totalidade social onde o trabalho docente se exerce com a perda progressiva de autonomia e ingerência do poder institucional. Mas a ação educativa permanecerá sempre como um espaço de trabalho, de criação mediado pelos conhecimentos específicos e pelos saberes gerados na prática docente de cada professor,

Voltamos, assim, às perguntas iniciais: adaptar-se ou resistir? Como os sindicatos debilitados pela nova lei do trabalho organizarão suas lutas? O fim do imposto sindical 
obrigatório será um desafio de organização coletiva para os professores e os demais profissionais da educação fazerem frente à ofensiva empresarial. Neste período de extrema gravidade para as instituições democráticas, a adaptação ao momento é inevitável, mas não em sua integralidade.

A resistência faz parte da história das lutas para sobreviver aos desastres que atingem a humanidade. Somos chamados a conversar, a discutir, a romper os individualismos, as competições exacerbadas pelo sistema capital e seus desdobramentos (culturais, sociais, profissionais etc.) para reconstruir as instituições despedaçadas.

\section{REFERÊNCIAS}

AGAMBEN, G. (2004). Estado de exceção. São Paulo: Boitempo.

AZEVEDO, D. A. (2017 jun. 12). Cais do Valongo, o útero do país. O Globo, Rio, p. 17.

BARRETO, E. et al. (2017 jul. 16). Generosidade com propósito. O Globo, País, p. 3.

BAVA, S. C. (2015 abr.). Uma falsa polarização. Le Monde Diplomatique Brasil, n. 93, p. 3.

BOÉTIE, É. (2016) Discurso da servidão voluntária. São Paulo: Edit. Nós.

BONIFICAÇÃO por resultados. SEE-RJ, Rio de Janeiro, 2011. Recuperado de : $<w w w . e d u c a c a o . r j . g o v . b r$ Acesso em 3-11-2012>

CHALHOUB, S., \& SILVA, F T. (2009). Sujeitos no imaginário acadêmico: escravos e trabalhadores na historiografia brasileira desde os anos 1980. Cadernos AEL, 14, (26), 11-50.

CIAVATTA, M. (2015). O trabalho docente e os caminhos do conhecimento: a historicidade da Educação Profissional. Rio de Janeiro: Lamparina, 2015.

CIAVATTA, M. (1998). Qualificação, formação ou educação profissional: pensando além da semântica. Contexto \& Educação, 13(51), p. 51-66.

CIAVATTA, M., \& REIS, R. (2016). O passado escravista no presente: a sociologia histórica de Luiz Antonio Cunha. Revista HISTEDBR, 16(70), 70-86.

CIAVATTA, M., \& TREIN, E. A transformação do trabalho e a formação profissional na sociedade da incerteza. Uma contribuição ao pensamento histórico-crítico. In E. GRUNNER (Org.). Nuestra América y el Pensar Crítico: fragmentos de pensamiento crítico de Latinoamérica y el Caribe (pp. 187-216). Buenos Aires: CLACSO.

CUNHA, L. A. (2000). O ensino de ofícios artesanais e manufatureiros no Brasil escravocrata. São Paulo: UNESP; Brasília: FLACSO.

ESPÓSITO, I. R. (17 mar. 31). Com vetos, Temer sanciona lei que permite terceirização da atividade-fim. Agência Brasil. Recuperado de: <http://agenciabrasil.ebc.com.br/politica/noticia/2017-03/temer-sanciona-lei-que-permiteterceirizacao-em-atividade-fim-das-empresas $>$.

FERNANDES, F. (1972). Capitalismo dependente e classes sociais na América Latina. Rio de Janeiro: RJ Zahar Editores. 
FREITAS, L. C. (2016). Prefácio. In E; M. MARTINS. Todos pela Educação: como os empresários estão determinando a política educacional brasileira (pp. 9-10). Rio de Janeiro: Lamparina.

FRIGOTTO, G. (2017). Escola "sem" partido; esfinge que ameaça a educação e a sociedade brasileira. Rio de Janeiro: UERJ/LPP.

GORENDER, J. (2016). A escravidão reabilitada. São Paulo: Expressão Popular.

MAESTRI, M. (2016). A escravidão reabilitada: um clássico volta à vida. Apresentação. In J GORENDER, A escravidão reabilitada (pp. 7-17). São Paulo: Expressão Popular.

MAMIGONIAN, B. (2017) Escravos livres: a abolição do tráfico de escravos no Brasil. São Paulo: Companhia das Letras.

MARINI, R. M. (2000). Dialética da dependência. Petrópolis, RJ: Vozes.

MARTINS, E. M. (2016). Todos pela Educação: como os empresários estão determinando a política educacional brasileira. Rio de Janeiro: Lamparina.

MORAIS, J. K. C. (2017) de. Os saberes docentes necessários ao trabalho do professor de biologia no ensino médio integrado. Natal, 2017. Dissertação de Mestrado em Educação. Instituto Federal de Educação, Ciência e Tecnologia do Rio Grande do Norte.

OLIVEIRA, F. (1991). Uma alternativa democrática ao liberalismo. In F WEFFORT et al. $A$ democracia como proposta (pp 77-92). Rio de Janeiro: IBASE, 1991.

PATAH, R. (2017 jun. 22). Capitalismo jabuticaba. Folha de São Paulo, Opinião, p. A3bbbb.

PIOVESAN, Flávia. Legítima razão. O Globo, Opinião, 17 de novembro de 2011, p. 7.

PIRRÓ E LONGO, W. (2007). Alguns impactos sociais do desenvolvimento científico e tecnológico. CREA-RJ. Rio de Janeiro.

REIS, J. J. (1986). Rebelião escrava no Brasil: a história do levante do malês em 1835. São Paulo, Cia das Letras.

TARDIF, M (2014). Saberes docentes e formação profissional (14a ed.). Petrópolis: Vozes. 